\title{
Basisteoretiese perspektiewe op kommunikasie in die bediening
}

\author{
C.J.H. Venter
}

Dept. Diakoniologie \& Missiologie

Potchefstroomse Universiteit vir $\mathrm{CHO}$

POTCHEFSTROOM

\begin{abstract}
The issue dealt with in this article is the extracting of certain basictheoretical perspecives from Scripture, especially from the New Testament, to seme as guidelines for communication in the ministry. The following features are investigated: the source of the conmunication, the action and content of communication, the manifestations of communication, the role of the Holy Spiril in equipping man to communicate. Furthermore the requirements set by Scripture for the communicator, the modus (way) of communication and the authority in communication are also discussed. In conclusion certain basic-theoretical theses for communication in the ministry are postulated.
\end{abstract}

\section{Omskrywing van terminologie}

Sekere begrippe wat telkens in hierdie artikel gebruik word, vereis vooraf nadere omskrywing.

* Onder kommunikasie word bedoel dat daar 'n sender is wat sy boodskap deur die medium van gesprek (= taal) duidelik aan 'n ontvanger wil oordra. -

* Met basisteorie word bedoel die ontginning van teologiese vertrekpunte, primêr vanuit die Skrif, vir bepaalde areas (i.c. kommunikasie) in die vakgebied van die Diakoniologie.

* Die tern metateorie dui hier 'n teorie aan waarin wetenskaplike vertrekpunte uitgespel word wat raakvlakke met ander vakke deel, vakke wat aspekte van dieselfde aard bestudeer (vgl. Pieterse, 1993:41). 'n Vak soos Kommunikasiekunde deel byvoorbeeld met Homiletiek die aspek van die oordrag van 'n boodskap. 


\section{Aktualiteit van die onderwerp}

In toepaslike teologiese literatuur is dit al 'n gemeenplaas om te stel dat die vak Hermeneutiek tans in die brandpunt van filosofiese en teologiese besinning staan (Schoeman \& Van Veuren, 1987:111). In die beoefening van die Hermeneutiek word die terrein van die vak nie net meer beskou as die daarstelling en ontginning van reels vir Skrifverklaring nie, maar as die vak wat te doen het met die hele proses van verstaan. Henneneutiek is dus die vak waar die wisselwerking tussen die teks van die Woord en die teks van die lewe plaasvind (Müller, 1992:27-39).

Dit is egter nie net op die vlak van die Hermeneutiek waar verskuiwings plaasgevind het nie, maar ook op die vlak van die Homiletiek: die grootste verskuiwing hier vind plaas deurdat die fokus op die Bybelteks verskuif na die fokus op die hoorder (Van der Vyver, 1990:3-5), van uitleg na resepsie, van gerigtheid op heilsfeite na gerigtheid op geloofskommunikasie (Dingemans, 1992:126-127). In die lig van bogenoemde verskuiwing is dit dan ook nie eienaardig nie dat die vak Praktiese Teologie se taak omskryf word as die bestudering van kommunikatiewe handelinge in diens van die Evangelie (vgl. Firet, 1987:7, Muller, 1983:79).

In sy eenvoudigste vorm bestaan kommunikasie uit 'n sender, 'n boodskap, 'n medium, 'n kanaal en ontvanger. Juis vanuit Prakties-Teologiese besinning is gedurende die afgelope jare op metavlak indringende aandag gewy aan kommunikasie, in besonder op die vakgebiede van Homiletiek en Pastoraal.

Vir die onderwerp van hierdie artikel is dit van belang on kortliks op aspekte van hierdie besinning te wys. Pieterse (1987:23-26) wys op verskeie kommunikasiemodelle wat deur die eeue gegeld het. Reeds Plato het aan kommunikasie aandag gewy en Aristoteles ontwerp die sogenaande historiese kommunikasiemodel van spreker, boodskap, gehoor. Hierdie historiese model het vir eeue diens gelewer aan die Retoriek. Die vader van die moderne kommunikasiewetenskap is Kierkegaard. Hy stel die ontvanger van die kommunikasie sentraal in die proses van kommunikasie, en wel op gelyke vlak met die sender. Alleen as die ontvanger geinterpreteer het, het komınumikasie werklik plaasgevind. Met hierdie stelling het Kierkegaard in 'n sin die grondslag vir die modeme kommunikasiekunde gelê. Verskillende kommunikasiemodelle het sedertdien ontwikkel. Op die Suid-Afrikaanse toneel wy Pieterse (1991) basies 'n hele werk, Gemeente en prediking, aan besinning oor kommunikasie in die prediking. Hy gaan hierby in diepte in op die hermeneutiek van die hoorder (1991:97-127). Kellernan (1993:1-22) ondersoek op sinvolle wyse hoe strukturering met 'n kommunikatiewe intensie funksioneel kan wees (1993:16-17). Op die Nederlandse vakgebied verken Dingemans (1991:137-148) metateoreties die liniêre, sirkulêre en interaksionele simboolkommunikasiemodelle om dit te beoordeel en aan te wend vir die prediking. 
Hierdie kursoriese oorsig beklemtoon die belangrikheid van metateoretiese insette vir kommunikasie in die bediening. Uit dieselfde verkenning blyk egter ook duidelik dat basisteoretiese fundering van kommunikasie in die bediening nadere aandag behoort te ontvang. Weliswaar noem Pieterse (1991:21-25) bepaalde basisteoretiese riglyne vir kommunikasie in die prediking. Hierdie riglyne is onder andere dat die gemeente ontstaan deur die prediking; dat Christus self in sy Woord teenwoordig is; dat die ontvangers van die kommunikasie uit die Woord self 'n kommunikatiewe gemeenskap is deurdat hulle in gemeenskap met God en met mekaar staan. Kellerman (1993:2) se basisteorie vir die prediking is dat prediking "koninkryksgebeure is wat as bediening van die Woord van God die uitleg en toepassing is van die Godsopenbaring aan die mens van die hede in sy konkrete bestaan met die oog op geloofsvorming, geloofsgroei en geloofslewe tot eer van God". In 'n onlangse artikel word enkele basisteoretiese momente vir kommunikasie in die prediking aangedui (Venter, 1992:11-12). Wat in genoemde artikel kortliks aangedui is, word die onderwerp vir die huidige artikel, naamlik om deur basisteoretiese besinning bepaalde dieptesnitte te mak uit toepaslike Skrifgedeeltes en sodoende kommunikasie in die bediening nader te fundeer.

Die hipotese vir hierdie navorsing is dat die Skrif gegewens bied wat basisteoreties ontgin behoort te word met die oog op kommunikasie in die bediening.

Die metode wat gevolg sal word, is dié van analise en interpretasie. Die hooffokus sal val op die Pastorale Briewe omdat van die mees sentrale openbaring op die bediening hierin gevind word (vgl. Pelser, 1984:174).

\section{Ontginning van basisteoretiese perspektiewe met die oog op kommunikasie in die bediening}

\subsection{Die bron vir kommunikasie}

Ten opsigte van hierdie aspek word besondere aandag gewy aan 2 Timoteus 3:14.

Kommunikasie en die Bron waaruit kommunikasie behoort plaas te vind, word in 2 Timoteus 3:14 nóú verbınd in die uitdrukking: "Die hele Skrif is geïnspireer en het groot waarde om in die waarheid te onderrig, dwaling te bestry en verkeerdhede reg te stel."

Die waarheid dat die Skrif die bron is van waaruit kommunikasie langs die kanaal van bediening plaasvind, is geleè in die gegewe dat die Skrif geïnspireer (theopneustos) is. Rienecker (1980:301) wys daarop dat die Rabbyne reeds geleer het dat die Gees van God op die profete gerus en deur hulle gepraat het sodat hulle woorde nie van hulleself was nie "but from the mouth of God". Dieselfde 
gedagte kom na vore in 1 Petrus 4:11: "As iemand die gawe ontvang het om te preek moet God deur hom aan die woord kom."

Die kommunikasiegestaltes wat in 2 Timoteus 3:14 direk aan die Woord as Bron verbind word is weerlegging (elengmos), regstelling - letterlik regopstelling - van verkeerdhede en die aanleer van die regte lewenswyse. In hierdie gedeelte word die ontvanger van kommunikasie gesien as die man in diens van God. Die doel van kommunikasie is die volkome voorbereiding en toerusting vir elke goeie werk; dus "the Christian Minister has in his hands a God-given instrument, designed to equip him completely for his work" (Guthrie, 1973:165).

Die bron van kommunikasie in die bediening is die Skrif wat verkondig word in verskillende bedieningsgestaltes.

\subsection{Die aksie en inhoud van kommunikasie}

\subsubsection{Verbinding van 'n sentrale kommunikasiehandeling met die sentrale inhoud van die Nuwe Testament}

Dit is sekerlik so dat verskillende begrippe in die Nuwe Testament die aksie van kommunikasie kan aandui. Moontlik kan die begrip diakonein as die matriks van kommunikatiewe aksie genoem word. In sy indeks van begrippe toon Louw en Nida (1989:59) aan dat die begrip diakonein 'n spektrum kan beslaan wat die volgende kan insluit: dien, sorg, voorsiening maak. Die blote feit dat ' $n$ bedienaar as diakonos aangedui word, hou reeds 'n kommunikatiewe handeling in. "Der diakonos Christou ist auch diakonos der Gemeinde - die Bildsprache des Kultmahls wirkt weiter in" (Holtz, 1980:104). Hy wat bedien, kommunikeer met mense wat bedien word. Wie is hulle? Wat is hulle situasie? Watter voedsel het die gemeente nodig en hoe moet hierdie voedsel voorberei en aangebied word?

In verband met bogenoemde is dit veelseggend dat die Griekse kommunikasiemetafoor temno in 2 Timoteus 2:15 weergegee word met "suiwer verkondig". Rienecker vestig die aandag op die wye gebruik van hierdie begrip (1980:295-6), byvoorbeeld om reguit langs ' $n$ lyn te sny, 'n steen reg te sny om in 'n spesifieke plek in te pas of om 'n porsie vleis af te sny vir huishoudelike doeleindes. Toegepas sou gesê kon word dat "suiwer verkondig" hier die nuanse het om die waarheid in 'n bepaalde situasie reg en toepaslik te kommunikeer "not abridging it, not handling it as a charlaten ..." (Earle, 1977:235).

\subsubsection{Wat word gekommunikeer?}

Kan ' $n$ bepaalde sentrale inhoud wat gekommunikeer moet word in die Nuwe Testament aangedui word? 'n Locus classicus in hierdie verband is 2 Korintiërs 
5:18-20: God het die wêreld met homself versoen en aan ons die bediening van die versoening gegee. Die begrip wat hier vir versoening gebruik word (katallassein) het die nuanse van omruiling. Luther het hierdie omruiling waar sondaars Christus se plek voor God inneem en Christus sondaars se plek voor God inneem, genoem: God se vrolike ruil. Op hierdie versoening, hierdie ruiling van plekke, is die kommunikasie-aksie van bediening (diakonem) gerig.

Dit is insiggewend om daarop te let dat die verbinding van kommunikasie en die sentrale inhoud van die Skrif ook besonder sterk voorkom in die Pastorale Briewe, maar dan in ander bewoording en begrippe as in 2 Korintiërs 18:20, byvoorbeeld in Titus 2:11-14 en in Titus 3:4-8. Op gegewens in die perikoop Titus 2:11-14 word nou nader ingegaan.

Eerstens word, wat die wyer struktuur van die perikoop betref, gewys op die opeenstapeling van drie kommunikasie-aksies, naamlik lalei, parakalei en elenge. Hierdie kommunikasiebegrippe vertoon 'n herhalingspatroon met Titus $2: 1$ waarin - feitlik woordeliks - dié drie begrippe ook gebruik word. Hierdie klimaktiese opstapeling van kommunikasie-opdragte verleen 'n dringendheid aan die kommunikasie. Dié kommunikasie roep na 'n bepaalde inhoud.

Wat moet gekommunikeer word? In kem word die versoening - as sentrale inhoud van die Nuwe Testament - hier aangedui in die uitdrukking "die genade van God ons Verlosser het aan alle mense verskyn".

Die verskyning van die genade van God ons Verlosser staan hier voorop. Die aoristustyd dui aan dat die verskyning vir eens en vir altyd finaal plaasgevind het In Hellenistiese Grieks het hierdie begrip onder andere die amptelike besoek van 'n keiser of ander hooggeplaaste aangedui. So 'n besoek het gepaardgegaan met genadebewyse, byvoorbeeld geskenke of vrylating van gevangenes (vgl. Schierse, 1968:165-166). Die begrip verskyning word egter nooit van God as Persoon gebruik nie, maar wel van die inwerkingtreding van sy genade (vgl. Ridderbos, 1967:27), met ander woorde van die realisering van sy aksie van versoening.

Die spesifieke aanduiding (rod ons Verlosser is in die Pastorale Briewe tipies Paulinies (vgl. 1 Tim. 1:1, 3:3, 4:10, Tit. 1:3, 2:10 en 3:4). Die verklaring hiervoor is dat God, die Verlosser, onderskei moes word van destydse heersers wat hulleself ook verlosser genoem het ondat hulle gemeen het dat juis hulle vir hulle volk geluk en welstand bring (Venter, 1992:17). Daarteenoor staan God, dié Verlosser, wat die wêreld met Homself versoen en sodoende verlos het uit die verderf.

Uit die verkenning van bogenoemde Skrifgegewens is die afleiding dus gewettig dat God se versoening, sy omruiling, die sentrale inhoud van die kommunikatiewe 
handelinge (diens) is. Anders gestel: die hoofinhoud van die Skrif roep om kommunikasie en kommunikasie geskied vanuit die sentrale inhoud van die Skrif.

\subsection{Die gestaltes van kommunikasie}

In die aanduiding van die gestaltes van kommunikasie sal uiteraard aandag gewy moet word aan Woordbedieningsbegrippe in die Nuwe Testament. Dingemans (1991:37) onderskei veral vier gestaltes van preekkommunikasie, naamlik kerug$m a$, didache marturion en homilia. Firet (1974:60-118) het aangetoon dat die grondgestaltes van die kommunikasie van die evangelie dié is van kerugma, didache, paraklese en kategese.

In 'n resente ondersoek (Venter, 1992:6-10) word aangetoon dat in die Pastorale Briewe agt Woordbedieningsbegrippe voorkom (parakalein, paraggellein, elegchein, didaskein, kerussein, epitiman, lalein en paideuein). Hierdie agt begrippe benadruk die wye veld van kommunikasie in die bediening. Sonder om elke begrip in besonderhede te omskryf, word die volgende konklusies van bogenoemde ondersoek soos volg verdiskonteer met die oog op gestaltes van kommunikasie in die bediening.

* Kommunikasie kan die gestalte aanneem van vermaning of vertroosting, van aankondiging, weerlegging, van lerende ontvouing van die Skrif, van die aankondiging van 'n nuwe stand van sake, van vertel, bestraf en leer.

* Vermaning, vertroosting, lering en bestraffing kan beskou word - hoewel nie met uitsluiting van ander nie - as kommunikasiegestaltes veral in herderlike bediening, dit wil sê in die modus van die paraklese.

* Lering (as ontvouing) en aankondiging van 'n nuwe stand van sake kan as hoofwyses van kommunikasie in die erediens beskou word.

* Vertel, leer en aankondiging kan in besonder ook as missiologiese kommunikasiegestaltes beskou word.

* Kommunikasie in die bediening geskied met gesag (vgl. 3.7).

* Kommunikasie moet plaasvind in ' $n$ gesindheid van lankmoedigheid, geloof en waarheid.

\subsection{Die toerusting tot kommunikasie}

Uit die Nuwe Testament blyk onmiskenbaar dat die gawe om te kommunikeer 'n gawe van die Heilige Gees is (charisma). Die begrip charisma dui in die Nuwe Testament nie uitsluitlik nie, maar tog wel op gawes wat kan dien tot opbou van die gemeente. 
In Romeine 12 en 1 Korintiërs 12 word 'n aantal Geestesgawes aan die gemeente genoem.

* In gelowige mense word die gawes saamgetrek in die gestalte van profete, leraars, evangeliste en voorgangers

* In menslike vermoëns word die geestesgawes geopenbaar in woorde van wysheid, besondere kragte, gawe van genesing, glossolalie, uitleg van tale, onderskeiding van geeste.

* In menslike handelinge kom die gawes tot openbaring in die gawe van vermaning, bediening en uitdeel.

In Filippense 1:1 word ook opsieners en diakens genoem en in 1 Timoteus 5:7 ouderlinge (vgl. Floor, 1979:101). Dit is opvallend dat nie minder nie as dertien uit die agtien gawes wat hier genoem word, direk met mondelinge kommunikasie te doen het!

Vir ons doeleindes is dit van belang on vanuit 'n kommunikasiehoek aandag te wy aan die gawe van die profeet. Dié gawe word in die ry van Geestesgawes tweede gestel ( 1 Kor. 12:28).

Floor (1979:104-106) kell aan die profesie as kommunikasie die volgende eienskappe toe:

* Profesie is ' $n$ besondere uiting van die Gees en geskied onder direkte aandrang van die Heilige Gees.

* Die openbaringskarakter van die profesie kom tot uiting in die inhoud van wat gesê word. Die profeet ontvang insig in dié verborgenhede van God en verklaar die bedoeling van die voortgang van God se heilshandeling.

* Finaliter is 'n profeet nie 'n blote toekomsvoorspeller nie, maar iemand wat die Geestesgawe het om die hand en wil en doel van God in die verlede, hede en toekoms - onder verligting van die Heilige Gees - raak te sien en te kommunikeer.

Profeet en kommunikasie is onlosmaaklik verbind aan die Gees, sowel wat oorsprong as toerusting betref.

Onder hierdie afdeling word ook gewys op die opdrag in 1 Timoteus 4:14 en 2 Timoteus 1:6 om die gawe - ook die gawe van kommunikasie - aan te wakker en nie te verwaarloos nie. Die opdrag aanwakker word korrek weergegee in die 1983-Afrikaanse Bybelvertaling met "soos 'n vuur aanblaas" - letterlik weer lewe in die vuur blaas. Lewe en vuur word elders in die Nuwe Testament direk in verband met die Heilige Gees se werk gebring (Joh. 6:3, Hand. 2:3). Daar is maar een Toeruster tot kommunikasie - die Heilige Gees. 


\subsection{Die vereistes vir kommunikasie}

Op metateoretiese vlak word besondere aandag gewy aan die kommunikasievereistes vir die sender. Veral vanuit die hoek van die Psigologie is hieraan breedvoerig aandag gewy. Die vereistes om te kommunikeer kan vanuit die gesigspunt van die Psigologie "... gereduseer word tot die basiese vermoëns van empatie, warmte en egtheid" (De Klerk, 1975:84, vgl. ook Van Arkel, 1986:2438, Firet, 1974:305-310, Venter, 1976:253).

Op basisteoretiese vlak toon ' $n$ nadere vergelyking van 1 Timoteus 3:2-7 en Titus 1:6-9 - die twee gedeeltes waarin die vereistes vir 'n bedienaar gestel word duidelik aan dat besliste kommunikasievaardigheid van hom verwag word.

Die vereiste dat 'n bedienaar bekwaam moet wees om te onderrig (didaktikos) of om met die gesonde leer te kan vermaan, moet beskou word as 'n primêre kommunikasievereiste. In hierdie vereiste trek die Bron van kommunikasie en sender saam, asook die wyse van kommunikasie (onderrig). 'n Aantal vereistes wat direk verband hou met die persoonlikheid van die kommunikeerder van die Evangelie word voorts gestel in 1 Timoteus 3:2-7 en Titus 1:6-9.

Om in diepte te kommunikeer moet die bedienaar nie 'n vegter, strydlustig of opvlieend wees nie. Hierdie eienskappe blokkeer of vernietig kommunikasie. Dit is opvallend dat, binne die raamwerk van doelmatige kommunikasie, die vereiste on nie strydlustig op te tree nie, vir almal geld, maar dat strydlustigheid totaal verbied word in herderlike kommunikasie met 'n bejaarde (1 Tim. 5:1). Die bedienaar se kommunikasie moet eerder daarop gemik wees om 'n geveg (getwis) te vermy. Met hierdie eienskap klop die gelykluidende: nie opvlieênd wees nie.

Om in diepte te kommunikeer moet die bedienaar ook vriendelik wees (epieikes). In 2 Korintiërs 10:1 word dieselfde begrip in verband met Christus gebruik en word dit in vertaalde vorm weergegee met (nederig) en vriendelik. Die kommunikasie-vereiste het hier in besonder die konnotasie van nederige standvastigheid wat onregverdigheid en swak behandeling sonder haat kan verdra, "trusting in God in spite of it all" (Rienecker, 1980:139).

'n Volgende vereiste wat direk betrekking het op die kommunikasie van die bedienaar, is die vereiste van ingetoënheid of selfbeheersing (sofron en enkrates) in 1 Timoteus $3: 2$ en Titus 1:18. Dit is opvallend dat juis die gawe van selfbeheersing in Galasièrs 5:22 klimakties as hoogste vrug van die Heilige Gees genoem word. Inderdaad, die hoogste bewys van die werking van die Heilige Gees in ' $n$ gelowige is selfbeheersing, en daarom is hierdie eienskap onmisbaar vir kommunikasie in die bediening. 
Die vereistes vir kommunikasie wat hierbo aan die orde gestel is, het ' $n$ beslissende invloed op kommunikasie in die bediening. Op metateoretiese vlak is byvoorbeeld vanuit die Psigologie duidelik aangetoon dat aggressie meermale ' $n$ ontvlugtingsreaksie kan wees en destruktief werk (vgl. Venter, 1976:1956). As 'n pastor byvoorbeeld ' $n$ oordrag van aggressie van die kant van 'n lidmaat met aggressie beantwoord, is die kommunikasie verbreek en kan dit alleen met moeite herstel word.

\subsection{Die wyse van kommunikasie}

\subsubsection{Verhouding as voorvereiste vir kommunikasie}

Vanuit 'n kommunikasiehoek gesien, word algemeen erken dat die verhouding waarin 'n bedienaar tot 'n lidmaat staan, deurslaggewend is vir sinvolle kommunikasie (vgl. Pieterse, 1987:29-30). Gemeentelede wat 'n minder gunstige verhouding met of opvatting van die bedienaar het, lusster ook deur dié filter na sy kommunikasie.

Die vraag waarop hier nader ingegaan word is of die Nuwe Testament, in besonder die Pastorale Briewe, bepaalde gegewens bied oor die belang van verhouding in kommunikasie. Twee aspekte word nader ontgin.

\subsubsection{Die huisgesin-metafoor}

In I Timoteus 3:4 word 'n bepaalde kommunikasie- of verhoudingsvaardigheid van die bedienaar verwag. Hy moet iemand wees wat aan sy vrou getrou is en sy kinders moet gelowig wees. Die metafoor van die huisgesin druk per definisie kommunikasie in verhouding uit. Ondat die metafoor van die huisgesin ook op die gemeente, die huisgesin van God (1 Tim. 3:15) betrek word, geld die eis van kommunikasievaardigheid ook vir die bedienaar in sy verhouding tot die gemeente.

Op 'n baie praktiese wyse word kommunikasievaardigheid binne ' $\mathrm{n}$ bepaalde verhouding in 1 Timoteus 5:1 gestel: 'n bejaarde moet jy nie hard vermaan nie, maar soos 'n vader, dit wil sê soos in die verhouding van 'n seun tot sy vader. 'n Bejaarde vrou moet vermaan word soos in die verhouding seun tot moeder.

Die innige verband tussen die bedienaar se kommunikasie in sy eie huis en in God se huisgesin word nader aangedui in I Timoteus 3:5 en 5:17. In sy eie huis word die bedienaar se kommunikasie uitgedruk in die aksie van prostenai (1 Tim. 3:5) en in God se huisgesin is dit proestotes preshutero wat kommunikeer In albei gevalle word dieselfde begrip vir die kommunikasie-aksie gebruik. Hierdie begrip - proïstamenos - word ook in Romeine 12:8 as 'n charisma van die 
Heilige Gees aangedui. Die uiters belangrike konsekwensie van hierdie basisteoretiese vasstelling is dat die bedienaar wat kommunikasie-in-verhouding in sy eie gesinsopset verwaarloos of verontagsaam, hom nie op die leiding van die Heilige Gees kan beroep vir sy kommunikasie in die gemeente, die huisgesin van God nie.

\subsubsection{Die aanspreekvorme in die Pastorale Briewe as kommunikasie in verhouding}

Die volgende aanspreekvorme word as toepaslik beskou vir nadere ondersoek in hierdie artikel.

Paulus spreek Timoteus en Titus aan as: my ware kind (1 Tim. 1:2), my kind Timoteus (1 Tim. 1:18), my geliefde kind (2 Tim. 1:2), my seun (2 Tim. 2;1), my ware kind (Tit. 1:3).

Hierdie aanspreekvorme dui deurgaans op 'n sterk kommunikasieverhouding tussen Paulus en sy twee jong medewerkers. Die intense vertrouensverhouding wat spreek uit my ware kind, dit wil sê my egte, geliefde kind, is aanduidings van 'n oop en innige kommunikasieverhouding.

Die ruimte waarin die kommunikasieverhouding ontstaan en groei, is die geloof nog nader aangedui in Titus 1:3 as ons gemeenskaplike geloof. Die diepste kommunikasie vind daar plaas waar sender ( $=$ bedienaar) en ontvanger van die bediening op dieselfde gemeenskaplike geloofsgrondslag staan. Hierdie gemeenskaplike geloof is die ruimte van die nuwe bestaanswyse (Ridderbos, 1967:43) in die nuwe versoende verhouding van hulle wat die Evangelie aangehoor en aangeneem het.

Die feit dat die bepaalde aanspreekvorme telkens aan die begin van al drie die Pastorale Briewe voorkom, hou in dat alle kommunikasie wat verder in die brief volg, in die lig van die bestaande kommunikasieverhouding gesien moet word.

Die feit dat hierdie aanspreekvorme ook telkens in die briewe herhaal word (1 Tim. 1:18 en 2 Tim. 2:1), is geen formalisme nie, maar inteendeel 'n aanduiding dat die kommunikasieverhouding deurgaans funksioneer.

Bogenoemde basisteoretiese prinsipe van die gemeenskaplike verhouding tussen sender en ontvanger as grondslag vir kommunikasie, het 'n bepaalde raakvlak met die kommunikasiemodel wat as interaksionele simboolkommunikasie bekend staan. Hierdie model wat op metateoretiese vlak ontwerp is, wil Dingemans vrugbaar aanwend vir kommunikasie in die bediening, want dié model "veronderstelt dat er een voorgegeven betrokkenheid is van de hoorders en de spreker op een zaak waarover men samen wil spreken" (Dingemans, 1991:146). Hierdie 
sáámspreek tussen bedienaar en lidmaat kan finaliter net in diepte plaasvind as albei die gemeenskaplike geloof as grond het (vgl. ook Pieterse, 1991:103).

\subsubsection{Individualisering as voorvereiste vir kommunikasie in die bediening}

Wat massakommunikasie betref, word metateoreties dikwels gestel dat geslaagde kommunikasie plaasvind as 'n sender die ontvanger van die kommunikasie so benader dat hy die kommunikasie ontvang asof met hom persoonlik as enkeling gepraat word. Dit is belangrik dat in groepskommunikasie met hierdie beginsel rekening gehou word.

Basisteoreties gesproke is daar bepaalde kommunikasielyne in die Nuwe Testament wat bogenoemde bevinding nader kan begrond.

Die volgende word hier behandel:

* Uit 1 Timoteus 5:1-2 kom die perspektief na vore dat in kommunikasie geindividualiseer moet word ten opsigte van bepaalde leeftydsfases en die wyse waarop met 'n persoon in 'n bepaalde leeftydsfase gekommunikeer word:

\begin{tabular}{|l|l|}
\hline Leeftydsfase & Kommunikasie \\
Jongmanne & $*$ Vermaan soos 'n broer \\
Jonguroue & $*$ Vermaan soos 'n suster \\
Bejaarde man & $*$ Vermaan soos 'n seun sy vader \\
Ou vroue & $*$ Vermaan soos 'n seun sy moeder \\
\hline
\end{tabular}

* Dieselfde lyn van individualisering kom na vore waar met 'n gesin gekommunikeer word. Niemand is 'n nommer nie; elkeen het 'n woord in sy situasie nodig. In Efesiërs 5:22-25 kom hierdie kommunikasieperspektief só na vore:

\begin{tabular}{|l|l|}
\hline Vroue & wees onderdanig \\
Mans & julle moet julle vrouens lieflêe \\
Kinders & wees aan julle ouers gehoorsaam \\
Vaders & moet julle kinders nie terg nie \\
Slawe & wees aan julle base gehoorsaam \\
\hline
\end{tabular}


Ook in kommunikasie met verskillende geloofstipes moet geïndividualiseer word (1 Tess. 5:14).

\begin{tabular}{|l|l|}
\hline $\begin{array}{l}\text { Onordelikes } \\
\text { Kleinmoediges } \\
\text { Swakkes }\end{array}$ & $\begin{array}{l}\text { moet vermaan word } \\
\text { moet bemoedig word } \\
\text { moet ondersteun word }\end{array}$ \\
\hline
\end{tabular}

Dit is ook veelseggend dat hier gestel word dat alle kommunikasie in 'n gesindheid van geduld moet plaasvind.

\subsection{Kommunikasie en gesag}

Kommunikasie van die Woord van God kom met gesag tot die ontvanger. Die outoritêre aanwending van gesag kan kommunikasie egter ernstig skaad. Die vraagstelling is daarom: waarin is die gesag in kommunikasie uit die Woord van God geleë? Is die gesag geleë in die persoon van die kommunikeerder of in die Woord wat hy bedien?

Twee uitdrukkings in die Pastorale Briewe kan op hierdie vraagstelling lig werp. In die uitdrukking "dienskneg van Christus" (1 Tim. 4:6) en "slaaf van die Here" (Kurios) (2 Tim. 2:24) word die bedienaar en sy wyse van kommunikasie geskets. In homself is die bedienaar wat kommunikeer 'n dienskneg - meer nog ' $n$ slaaf. Van nature het 'n slaaf geen gesag nie; hy is totaal afhanklik van sy baas. Die gesag lê by die koning van die slaaf, maar - as die slaaf sê wat die koning sê, as hy dus die koning se woord oordra, dan verleen die koning self gesag aan sy slaaf se woord.

Ontsporing in kommunikasie vind dikwels plaas indien 'n bedienaar vir sy persoon of vir sy eie woord die gesag opeis wat alleen God en sy Woord toekom. Indien nie die Woord van die Kurios oorgedra word nie, word nie net die gesag van die Woord ondergrawe nie, maar ook die gesag van die Kurios van die Woord.

\subsection{Basisteoretiese perspektiewe op kommunikasie in die bediening - samevattende stellings}

* Die primêre Bron van kommunikasie in die bediening is die geïnspireerde Woord van God.

* Versoening as sentrale inhoud van die Skrif roep om kommunikasie en kommunikasie geskied vanuit dié sentrale inhoud. 
* In kommunikasie in die bediening tree in besonder die gestaltes van kerussein, didaskein, parakalein, elegchein, paraggellein en lalein na vore. Die gestalte van kommunikasie word bepaal deur die situasie van die subjek met wie gekommunikeer word

* Die Heilige Gees rus toe om te kommunikeer en staan sentraal by die oefening (aanwakker) van die kommunikasiegawe.

* Van die bedienaar van die Woord word besliste kommunikasievaardighede vereis. As primêre vereiste geld dat hy die Woord moet kan hanteer. Met die oog hierop moet sy persoonlikheidsamestelling sodanig wees dat hy nie 'n vegter is nie, maar nederig, vriendelik en selfbeheersd moet kan kommunikeer

* Vir bedieningskommunikasie is die verhouding van leraar tot gemeentelid deurslaggewend. Hierdie verhouding groei en geskied binne die nuinte van die gemeenskaphke geloof.

* Sinvolle kommunikasie vereis individualisering ten opsigte van leeftydsfase, situasie, geslag, geloofstipe, gerigtheid van kommunikasie uit die Woord en gerigtheid in gebed op die bepaalde situasie.

* Gesag in bedieningskommunikasie is nie geleë in die persoon van die kommunikeerder nie maar in die Woord van sy Sender.

\section{Bibliografie}

DE KLERK, W J 1975 Pastorale sensitiwiteit Johannesburg : Perskor

DINGEMANS, G D J 1991 Als hoorder onder de hoorders Hermeneutische Homiletiek Kampen Kok

DINGEMANS, G D J 1992 Ontwikkelingen in de Homiletiek Een overzicht van recente literatuur Nederlands Theologisch Tydschrift, 46(2) 124-131

EARLE, R 1977 Word Meanings in the New Testament Grand Rapids : Baker

FIRET, J 1974 Het agogisch moment in het pastoraal optreden Kampen: Kok

FIRET, J 1987 Spreken als een leerling Praktisch theologische opstellen Kampen Kok

FLOOR, L. 1979. Hy wat met die Heilige Gees doop Pretoria : NG Kerkboekhandel

GUTHRIE, D 1973. The Pastoral Epistles London Tyndale

HOLTZ, G 1980. Die Pastoralbriefe Berlin Evangelische Verlagsanstalt

KELLERMAN, J S 1993 Praktykteoriee: Preekvorme en -strukturering Ongepubliseerde voordrag gehou voor Werkgemeenskap vir Praktiese Teologie Potchefstroom Jan 1993.

L.OUW, J P \& NIDA, E A 1989 Greek-English Lexicon of the New Testament Based on Semantic Domains, I en II Goodwood United Bible Societies

MULLLER, B A 1992 Hermeneutiek op die intervlak tussen eksegese en sosiale analise Praktiese Teologie in Suid-Afrika, 7(1) 17-26

MULLER, J.C. 1983 Die homilie as wyse van eietydse prediking Pretoria : UP (DDproefskrif )

PELSER, G M M 1984 Die Pastorale Briewe (In Du Toit, A B red Handleiding by die Nuwe Testament V Pretoria NG-Kerkboekhande $p$ 174-198)

PIETERSE, H J C 1987 Communicative Preaching Pretoria: Unisa 
PIETERSE, H.J C. 1991. Gemeente en prediking Halfwayhouse : NG Kerkboekhandel

PIETERSE, H J.C. 1993. Praktiese Teologie as kommunikatiewe handelingsteorie Pretoria: Ongepubliseerde uitgawe

RIDDERBOS, H. 1967. De pastorale brieven Kampen : Kok

RIENECKER, F. 1980. A Linguistic Key to the Greek New Testament, Volume 2. Grand Rapids : Zondervan

SCHIERSE, F.J 1968 Die Pastoralbriefe. Düsseldorf: Patmos.

SCHOEMAN, J. \& VAN VEUREN, P. 1987. Filosofiese Hermeneutiek in gesprek met die vakwetenskappe. Gadamer en Ricoeur. (In Snyman, J.J. \& Du Plessis, P.G.W red Wetenskapsbeelde in die geesteswetenskappe. Pretoria : RGN. p. 111-134.)

VAN ARKEL, J.T de J. 1986. Persoonlikheid en ampsgeskiktheid van die predikant Praktiese Teologie in Suid-Afrika, 1: 24-38.

VAN DER VYVER, L. du P. 1990. Die rol van die hoorder in die prediking. Potchefstroom. (Verhandeling (Th M.) - PU vir CHO)

VENTER, C.J.H. 1976. Die bediening van die versoening aan die bejaarde. 'n Pastorale studie in die lig van die Pastorale Briewe. Potchefstroom : Pro Rege

VENTER, C.J.H 1992. Prakties-Teologiese grondslae van die prediking. Praktiese Teologie in Suid-Afrika, 7(1):1-16. 